\title{
In vitro antagonism of edible ectomycorrhizal fungi against Fusarium oxysporum and Fusarium verticillioides
}

\author{
by Jaime Olaizola Suárez ${ }^{1}$, Juan Alberto Pajares ${ }^{2}$ and Julio Javier Diez ${ }^{2 *}$
}

\begin{abstract}
Twenty-one isolates of edible ectomycorrhizal fungi (ECM) of 15 different species were tested in vitro for mycelial growth and spore germination against two isolates each of Fusarium oxysporum and F. verticillioides. The growth of Fusarium isolates was significantly inhibited when co-cultured with most of the 21 ECM fungi tested. Two ECM fungi (Ba-2 and Xf-2) failed to reduce the growth of Fusarium isolates. In paired cultures, growth of all Fusarium isolates was significantly reduced by Rhizopogon roseolus, Suillus luteus, Tricholoma portentosum, Amanita rubescens, Amanita ovoidea, Boletus fragrans and Laccaria laccata. Spore germination of all Fusarium isolates was strongly inhibited by culture filtrates of $R$. roseolus and the two S. luteus isolates. Different behavior between ectomycorrhizal fungi and Fusarium species, as well as among isolates of the same species was observed in both assays. Inhibition of Fusarium species suggests that several isolates of edible ectomycorrhizal fungi have a high potential for biological control of damping off. The effect of ECM fungi was less evident in the conidial germination assay than in the growth assay, although inhibition was also observed. The methodology presented here can be used as an effective tool for in vitro selection of ectomycorrhizal fungi and in nursery assays.
\end{abstract}

Keywords: biological control, edible ectomycorrhizal fungi (ECM), seedling diseases, in vitro selection, culture filtrates

\section{RÉSUMÉ}

On a testé in vitro 21 isolats de champignons ectomycorhiziens comestibles (ECM) de 15 espèces différentes sur leur capacité à inhiber la croissance mycélienne et la germination des spores de deux isolats de Fusarium oxysporum et de deux isolats de F. verticillioides. La croissance des isolats de Fusarium a subi une forte diminution lorsqu'ils étaient cultivés en paires avec presque tous les 21 champignons ECM testés. Deux champignons ECM (Ba-2 and Xf-2) nont pas réduit la croissance des isolats de Fusarium. Dans les cultures en paires, tous les isolats de Fusarium ont vu leur croissance fortement diminuée par Rhizopogon roseolus, Suillus luteus, Tricholoma portentosum, Amanita rubescens, Amanita ovoidea, Boletus fragrans et Laccaria laccata. La germination des spores de tous les isolats de Fusarium a été considérablement réduite par $R$. roseolus et des filtrats de culture de deux isolats de $S$. luteus. Le comportement de chacun des champignons ectomycorhiziens a varié selon l'espèce de Fusarium et l'isolat de chacun. L’effet d'inhibition exercé sur les espèces de Fusarium laisse voir que certains isolats de champignons ectomycorhiziens comestibles pourraient être utilisés dans la lutte contrôle biologique contre la fonte des semis. Les effets des champignons ECM auront moins manifestes lors des essais de germination des conidies que lors des essais de croissance, même s'il y a eu une certaine réduction de la germination. La méthodologie que nous présentons ici pourrait aussi servir pour la sélection in vitro de champignons ectomycorhiziens et pour diverses expériences en pépinière.

Mors-clés : lutte biologique, champignons ectomycorhiziens comestibles (ECM), maladies des semis, sélection in vitro, filtrats de culture

\section{Introduction}

The fungal genus Fusarium includes species that cause serious plant diseases which cannot be easily controlled in forest nursery crops and plantations all over the world, being responsible for substantial damage (Axelrood et al. 1995; Neff and Perrin 1999). Fusarium inoculum can be carried on seeds, containers, peat moss or in irrigation water (Hwang et al. 1995). Some species of this genus, for instance susceptible pines, can be seriously impacted by F. circinatum Nirenberg \& O'Donnell. threatening the sustainability of forests (Wikler et al. 2003; Landeras et al. 2005).
Several fungicides have been used to control damping off caused by Fusarium, but the suitability of chemical applications to manage this disease remains doubtful due to environmental consequences and low efficiency (Lamichhane et al. 2017), especially during the first stages of seedling growth in nurseries (Sinclair et al. 1975). Furthermore, several pathogenic fungi have developed resistance mechanisms against many fungicides (Lucas et al. 2015; Hu et al. 2016). Evidence suggests that some ectomycorrhizal (ECM) fungi behave as biological control agents and are able to reduce the damaging effects of plant pathogens. (Marx and Davey 1969; Duchesne

\footnotetext{
${ }^{1}$ ID Forest - Biotecnología Forestal Aplicada, Calle Los Curtidores 17, 34004, Palencia, Spain.

${ }^{2}$ Department of Plant Production and Forest Resources, University of Valladolid, Avenida de Madrid 44, 34071 Palencia, Spain.

*Corresponding author e-mail: jdcasero@pvs.uva.es
} 
1994; Annesi and Motta 1998; Pedersen et al. 1999; Chakravarty et al. 1999; Rudawska 2000; Martín-Pinto et al. 2006a; Zhang et al. 2011). The inhibitory effect caused by ECM fungi can be expressed through nutrient competition or the production of antifungal exudates, which may induce antibiosis and/or hyperparasitism when ECM fungi colonize the pathogen (Duchesne et al. 1987a; 1987b; 1988; 1989a; 1989b; Chakravarty et al. 1990; 1991). These mechanisms can be directly tested in vitro by ECM-pathogen co-cultures, or by ECM culture filtrates containing active substances involved in the process (Chakravarty et al. 1999).

Previous studies reported that the efficacy of these symbiotic fungi for plant protection against root pathogens varies among mycorrhizal species and among different isolates within the same species (Sampagni and Perrin 1985; Perrin and Soulas 1996; Zhang et al. 2017). Thus, considering such inter and intraspecific variation, it is advisable to test the highest number of ECM species and isolates for selecting candidates with effectivity against Fusarium spp. (Trappe 1977; Zhao et al. 1988).

Many studies on ECM fungi as biological control agents have tested poisonous species such as Paxillus involutus (Batsch ex Fries) Fries (Duchesne et al. 1987a; 1987b; 1988; 1989a; 1989b; Chakravarty et al. 1990; 1991) and only few studies have used edible species as Laccaria laccata (Scop. Ex Fr.) Berk. \& Br. (Chakravarty and Hwang 1991) or Suillus tomentosus (Kauff.) Singer, Snell and Dick (Hwang et al. 1995), therefore, the efficacy of edible ECM for control of damping off caused by Fusarium is largely unknown.

However, some edible ECM fungi with recognised economic value may be promising for protection of damping off in nurseries (Martín-Pinto et al. 2006a). These species may provide protection against pathogens and add economic value through the production of edible fruiting bodies following after planting.

Several species of the genus Lactarius (L. deliciosus L. Gray, L. semisanguifluus Heim \& Leclair. and L. sanguifluus (Paulet) Fr.) and Boletus (B. pinophilus Pilat \& Derm. B. edulis Bull.:Fr., $B$. aestivalis (Paulet) Fr. and B. aereus Bull.) are valued and consumed all over the world (Boa 2004). Moreover, other species such as Suillus luteus (L.) Roussel are commonly used in the food industry, as well as other less known species, for instance Amanita rubescens (Pers.: Fr.) S. F. Gray, Amanita ovoidea (Bull.: Fr.) Quèl., Boletus fragans Vittad., Laccaria laccata, Leccinum lepidum (Bouchet ex Ess.) Quadr., Rhizopogon roseolus (Corda) Th. M. Fr., Xerocomus ferrugineus (Schaeffer) Bon and Tricholoma portentosum (Fries) Quélet., which are consumed in some regions of Spain and in other countries (Martínez de Azagra et al. 1997).

The main goal of our work was to investigate the in vitro interactions between isolates of various edible ECM fungi against pathogenic strains of F. oxysporum Schlecht. Emend. Snyd. \& Hans. and F. verticillioides (Sacc) Niremberg (syn. F. moniliforme Sheldon), the main causal agents of damping off in Spanish forest nurseries (Martín-Pinto et al. 2006b). Specifically, the study aimed (1) to evaluate the effect of edible ECM fungi on growth of Fusarium spp. colonies, and (2) to assess the effect of edible ECM fungi culture filtrates on Fusarium spp. conidial germination.

\section{Materials and Methods}

\section{Fungal organisms}

Fifteen species of edible ECM fungi were selected by their ability to form ectomycorrhizal short roots (Trappe 1962) and their edible value (Sanchez and García 2006). ECM fungi were isolated using the Molina and Palmer (1982) methodology (Table 1), except Rr-1 and Ll-1 isolates that were provided by the Valonsadero Forest Research Center in Soria, Spain. A total of four virulent isolates of Fusarium were used, two F. oxysporum (Fo-4P and Fo-5P) and two F. verticillioides (Fm5P and Fm-6P) (Martín-Pinto et al. 2006a; 2008; Olaizola 2007). Single-spore cultures were obtained and subcultured every seven days on Difco PDA medium.

\section{Effect of ECM fungi on Fusarium growth}

The antagonistic effect of the 21 ECM isolates against $F$. verticillioides and F. oxysporum was studied on Modified Melin Norkrans (MMN) medium (Marx 1969) in 90-mm Petri dishes. The media was inoculated on the edge of the plates with ECM fungi by placing 5-mm agar plugs of each isolate taken from the periphery of 30-day-old mycelial mats. Cultures were allowed to grow at $22{ }^{\circ} \mathrm{C}$ in the dark, and after fifteen days 5-mm mycelial plugs from each Fusarium isolate were placed on the opposite side of the plate at a distance of 4 $\mathrm{cm}$. Antagonism was recorded daily for 10 days by measuring the radial growth of the Fusarium colonies. Each combination of Fusarium and ECM fungi was replicated five times.

\section{Effect of ECM fungi on Fusarium conidial germination}

The assay was carried out using Chakravarty and Hwang (1991) methodology with some variations as described next.

Table 1. Isolate code, species and main tree species of edible ectomycorrhizal fungi tested against pathogenic isolates of Fusarium

\begin{tabular}{lll}
\hline $\begin{array}{l}\text { Isolate } \\
\text { code }\end{array}$ & Species & Dominant tree species \\
\hline Ld-0 & Lactarius deliciosus & Pinus sylvestris \\
Ld-1 & Lactarius deliciosus & Pinus pinaster \\
Ld-2 & Lactarius deliciosus & Pinus sylvestris \\
Ls-3 & Lactarius sanguifluus & Pinus pinaster \\
Lm-1 & Lactarius semisanguifluus & Pinus pinaster \\
Ao-1 & Amanita ovoidea & Quercus ilex \\
Ar-1 & Amanita rubescens & Quercus ilex \\
Tp-1 & Tricholoma portentosum & Pinus sylvestris \\
Tp-2 & Tricholoma portentosum & Pinus sylvestris \\
Ll-1 & Laccaria laccata & Pinus sylvestris \\
Rr-1 & Rhizopogon roseolus & Pinus sylvestris \\
Bf-1 & Boletus fragrans & Quercus ilex \\
Ba-2 & Boletus aereus & Quercus ilex \\
Bv-1 & Boletus aestivalis & Quercus pyrenaica \\
Bv-2 & Boletus aestivalis & Quercus pyrenaica \\
Bl-1 & Leccinum lepidum & Quercus ilex/Q. faginea \\
Bl-4 & Leccinum lepidus & Quercus ilex/Q. faginea \\
Bp-1 & Boletus pinophylus & Castanea sativa \\
Sl-1 & Suillus luteus & Pinus sylvestris \\
Sl-2 & Suillus luteus & Pinus sylvestris \\
Xf-2 & Xerocomus ferrugineus & Quercus ilex \\
\hline & &
\end{tabular}




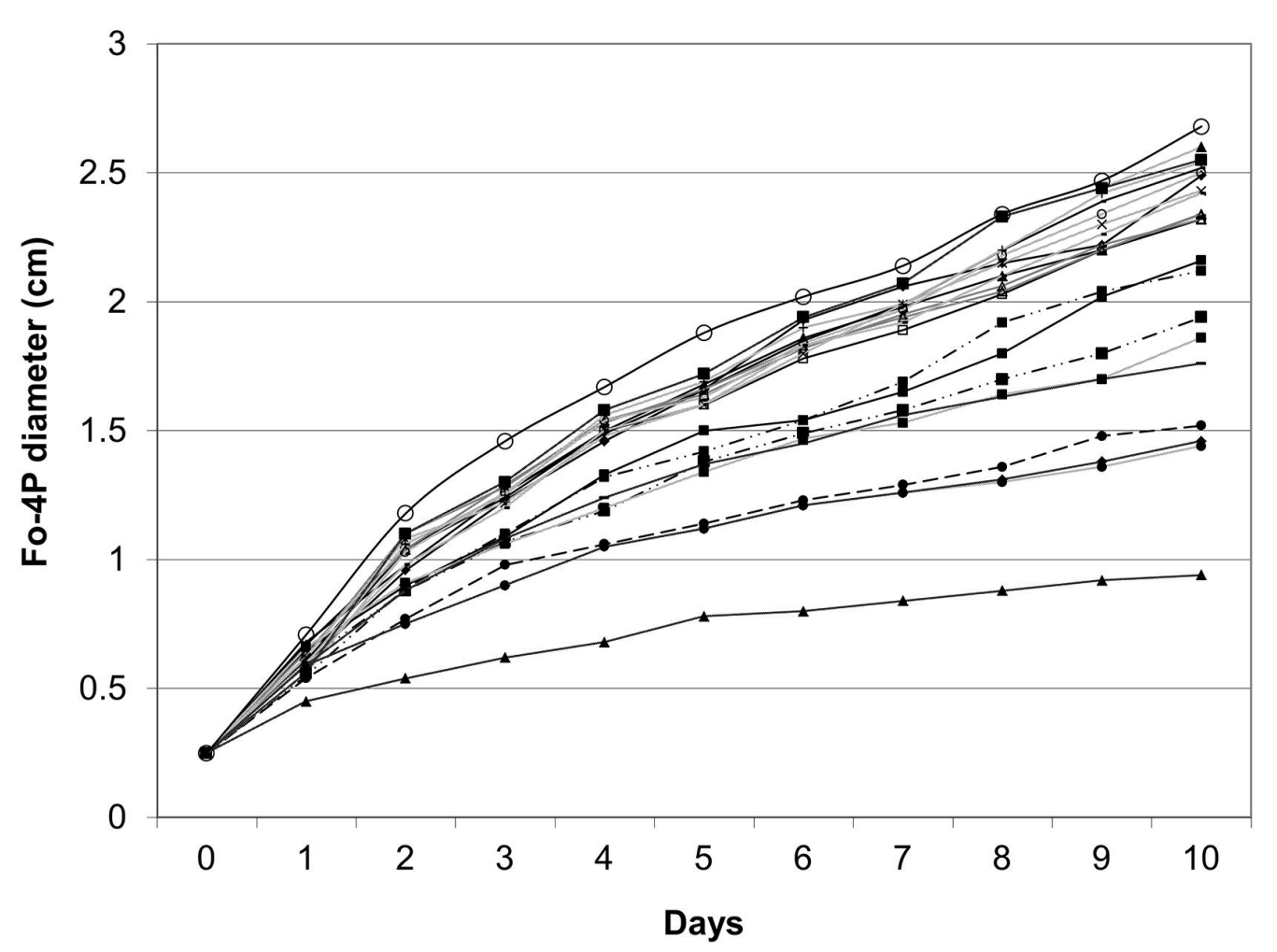

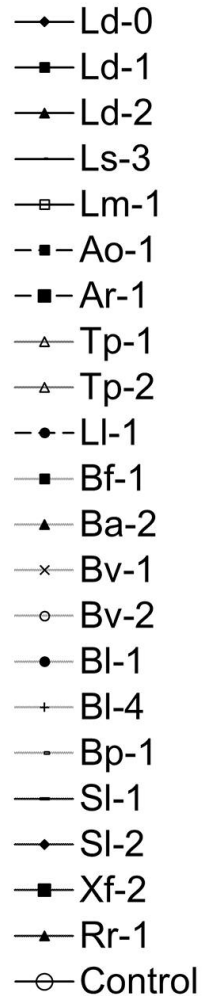

Fig. 1. Radial growth of Fusarium oxysporum (Fo-4P) in co-culture with 21 ectomycorrhizal fungal isolates (see Table 1 for the list of names]

To produce fungal culture filtrates, three agar plugs $(5-\mathrm{mm}$ diameter), removed from the periphery of 30 -day-old mycelial mats, were placed into $50 \mathrm{ml}$ Erlenmeyer flasks and maintained in $25 \mathrm{ml}$ liquid $\mathrm{MMN}$ medium at $22{ }^{\circ} \mathrm{C}$ in the dark on an orbital shaker (100 rpm). After 20 days, culture filtrates were collected by filtering through $0.20 \mu \mathrm{m}$ cellulose acetate syringe filters (Albet ${ }^{\circ}$ ). The filtrates were then stored in sterile Eppendorf tubes at $4^{\circ} \mathrm{C}$ in the dark. A conidial suspension was prepared with each Fusarium isolate by adding 3 $\mathrm{ml}$ of sterile distilled water into a six-day-old PDA culture, and the final conidium concentration was adjusted to $3 \cdot 10^{6}$ microconidia $\cdot \mathrm{ml}^{-1}$ by using a haemocytometer.

One hundred $\mu \mathrm{l}$ of the ECM culture filtrates per isolate and $100 \mu$ of the adjusted spore suspension of Fusarium were mixed in Eppendorf tubes and maintained in the dark at 22 ${ }^{\circ} \mathrm{C}$. We also set up a control treatment that contained $100 \mu \mathrm{l}$ of sterile liquid MMN and $100 \mu \mathrm{l}$ of the Fusarium conidia suspension. Spore germination of Fusarium was observed under the microscope at $0,6,12$ and 24 hours after confrontation. A total of 1200 spores were counted for each treatment (6 replicates of 200 spores each).

\section{Statistical analysis}

Data from both experiments were submitted to analysis of variance (ANOVA) to examine differences among Fusarium species and isolates, and to evaluate the effect of each ECM fungi against them using Statistica 5.5 software. The individual means were compared using the Least Significant Difference (LSD) test at $\mathrm{p}<0.05$.

\section{Results}

Effect of ECM fungi on Fusarium growth

Growth of the Fusarium isolates was significantly inhibited when co-cultured with most of the 21 ECM fungi tested (Figs. $1,2)$. Only two of the ECM fungi assayed (Ba-2 and Xf-2) failed to decrease the growth of any Fusarium isolate. ECM isolates Ao-1, Ar-1, Bf-1, Bl-1, Ld-2, Ll-1, Rr-1, Sl-2, Sl-1 and Tp-1 inhibited all Fusarium isolates. Of those, Bl-1, Rr-1 and Sl-2 had the highest inhibitory effect (LSD test: $p<0.05)$. In other cases, ECM fungi caused inhibition of three or two of the Fusarium isolates (Ld-1 or Lm-1 and Tp-2 isolates respectively) (Fig. 2). 

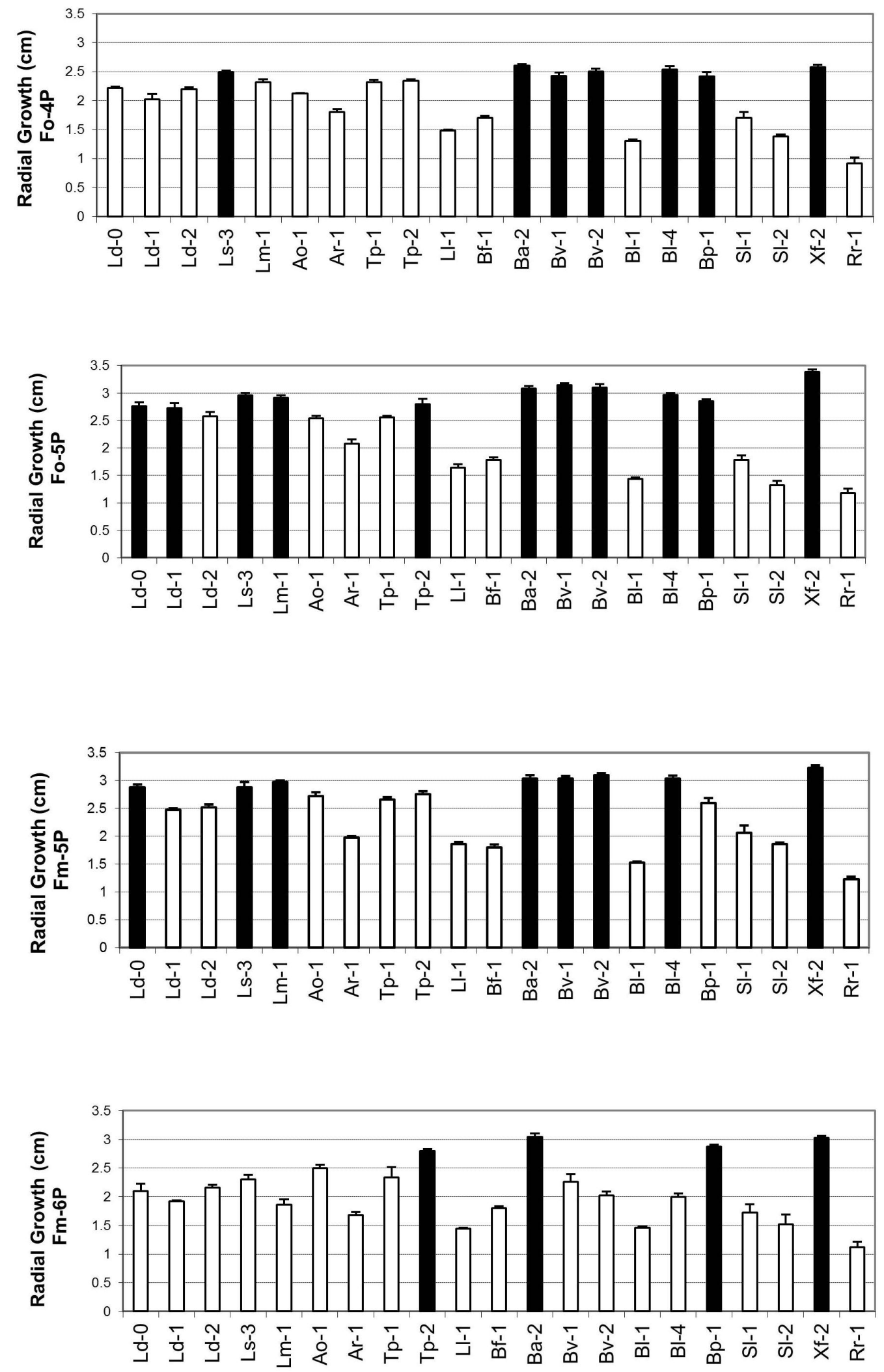

Fig. 2. Radial growth (cm) of two F. oxysporum isolates (Fo-4P and Fo-5P) and F. verticillioides isolates (Fm-5P and Fm-6P) in co-culture with 21 isolates of edible ectomycorrhizal fungi on agar plates after 10 days incubation. Black values are not significantly different compared to the control ( $p<0.05$ ) 
Intraspecific variation was observed among ECM isolates. Three Lactarius isolates caused inhibition of Fo-4P, however, only one isolate repressed growth of Fo-5P. Similarly, Tp-1 inhibited growth of the four Fusarium isolates, compared to Tp-2 that affected only Fo-4P and Fm-5P isolates. Regarding the Fusarium isolates, significant differences in growth were found when the four strains were compared independently (ANOVA, $\mathrm{p}<0.001$ ). However, we did not find significant differences in growth between the two Fusarium species when co-cultured with ECM fungi (ANOVA, $\mathrm{p}=0.639$ ), despite the observation that ECM fungi caused growth inhibition on both F. oxysporum isolates in 24 treatments compared to 30 in F. verticillioides (Fig. 2).

\section{Effect of ECM fungi on Fusarium conidial germination}

The effect of ECM fungi on the Fusarium conidial germination assay was less evident than in the growth assay although some degree of inhibition was indeed observed. The effect of ECM filtrates on Fusarium after 6, 12 and 24 hours strongly differed among mycorrhizal isolates (Fig. 3). No spores of Fusarium had germinated at the beginning of the experiment ( 0 hours), while at 6 and 12 hours germination was variable amongst isolates. After $24 \mathrm{~h}$, almost all spores in the control treatments germinated, therefore validating this time interval as optimal for comparison of Fusarium and ECM isolates (Fig. 4).

Many ECM fungal filtrates significantly inhibited spore germination of the four Fusarium isolates. There were significant differences in spore germination between both Fusarium species (ANOVA, $\mathrm{p}=0.004$ ) when treated with ECM culture filtrates. Twenty-five ECM isolates inhibited both isolates of $F$. verticillioides compared to $13 \mathrm{ECM}$ isolates which inhibited germination of both F. oxysporum isolates (Fig. 4). Differences were observed among the four Fusarium isolates (ANOVA, $\mathrm{p}<0.0001$ ). Fm-6P was the most susceptible isolate with reduced germination when placed together with 16 ECM isolates, whereas Fo-4P was the most resistant with decreased germination when exposed to 6 ECM isolates. Fm$5 \mathrm{P}$ and Fo-5P responded similarly to ECM fungal filtrates with reduced germination when combined with 9 and 7 ECM isolates, respectively.

Quantitatively, the culture filtrates from S. luteus (Sl-1, Sl2 ) and $R$. roseolus $(\mathrm{Rr}-1)$ were the most inhibitory, significantly reducing spore germination of all four Fusarium isolates (Fig. 4). ECM isolates greatly decreased spore germination of Fo-5P. Other ECM fungi appeared to cause a specific inhibition of particular Fusarium isolates. For instance, Tricholoma portentosum isolates (Tp-1 and Tp-2) produced the highest inhibition of Fm-5P, and Leccinum lepidum (Bl-1) was the most effective against Fm-6P. Four ECM culture filtrates (Bl-4, Ba-2, Ld-0, Lm-1) failed to affect either Fusarium isolate at the end of 24 hour period.

Similarly, as in the co-culture assay, intraspecific variation was observed between both Fusarium species and among ECM isolates (i.e., Ll-1 inhibited spore germination in Fo-5P, but not in Fo-4P, whereas Ld-2 inhibited spore germination in Fm-6P but not in Fm-5P ).

\section{Discussion}

Our study showed that several genera of ECM fungi have the potential for biological control of plant pathogens. The growth of all isolates of $F$. oxysporum and $F$. verticillioides was inhibited in dual cultures with L. deliciosus, S. luteus, A. rubescens, A. ovoidea, B. fragans, L. lepidum, L. laccata, T. portentosum and $R$. roseolus. Similar results were observed by Kope and Fortin (1989) and Morin et al. (1999) when assaying the effect of antimicrobial substances produced by diverse ectomycorrhizal fungi against different pathogenic agents. Rhizopogon roseolus and both isolates of S. luteus were the most efficient ectomycorrhizal fungi of the 21 ECM fungal isolates tested, causing inhibition of growth and spore germination in all four strains of Fusarium spp. Additionally, some other ECM fungi significantly reduced growth and spore germination in three, two or one of the Fusarium spp. isolates.

ECM isolates from the same species behaved similarly, though some clear intraspecific variations on Fusarium inhibition was observed. This was the case for Lactarius deliciosus and Tricholoma portentosum where we found differences in the behaviour of isolates. Isolates within the same species with differential efficiency against Fusarium were also found for Laccaria spp. (Perrin and Soulas 1996). The interaction of ECM fungi with root pathogens of pines is not well understood. Several authors have reported disease suppression by ECM fungi associated with fungal production of antimicrobial substances (Duchesne et al. 1987a; Chakravarty and Hwang 1991). Toxic effects of mycorrhizal fungi have been linked not only to plant pathogens, but also to insects (Halldorsson et al. 2000) and nematodes (Diedhiou et al. 2003). The antagonism of some ECM, such as L. laccata, on growth and spore germination of F. oxysporum and of F. verticillioides by toxic-like compounds was reported in previous studies conducted in our laboratory (Martín-Pinto et al. 2006a).

Suppression of Fusarium growth by ECM is likely caused in part by the production of antifungal compounds. Our results suggest that some ECM species release inhibitory substances into the medium, which are toxic to F. oxysporum and F. verticillioides. However, Boletus species had a reduced inhibitory effect and $X$. ferrugineus had no effect on Fusarium isolates. This different behavior indicates that under the assayed conditions, these isolates did not produce substances that were detrimental to Fusarium growth. However, plants use various defense mechanisms, including the production of antimicrobial compounds in the presence of ECM and the protective barrier effect provided by the presence of fungal mantle in the rhizosphere (Machón et al. 2006). Therefore, it is essential to also develop in vivo assays to test the inhibitory effect of ECM species on damping off in nurseries. This approach has been successfully tested for Laccaria laccata (Machón et al. 2006; 2009), Lactarius sanglifluus and Rhizopogon roseolus (Olaizola 2007), Suillus luteus (Mateos et al. 2017) and Amanita rubescens (Martinez et al. 2006) isolates.

Spore germination of F. oxysporum and F. verticillioides isolates was inhibited by the culture filtrates of some of the ECM fungi we assayed, but the effect was in general less marked than in the co-culture test. Our conidial germination experiment may demonstrate that inhibition of spore germination in F. oxysporum and in F. verticillioides was related to the production of antifungal compounds by some ECM isolates. While S. luteus (Sl-1, Sl-2), L. deliciosus (Ld$1, \mathrm{Ld}-2), R$. roseolus ( $\mathrm{Rr}-1)$ and $T$. portentosum (Tp-1) were the most active strains, other ECM fungi, such as Boletus aereus (Ba-2), Leccinum lepidum (Bl-4) or Lactarius semi- 

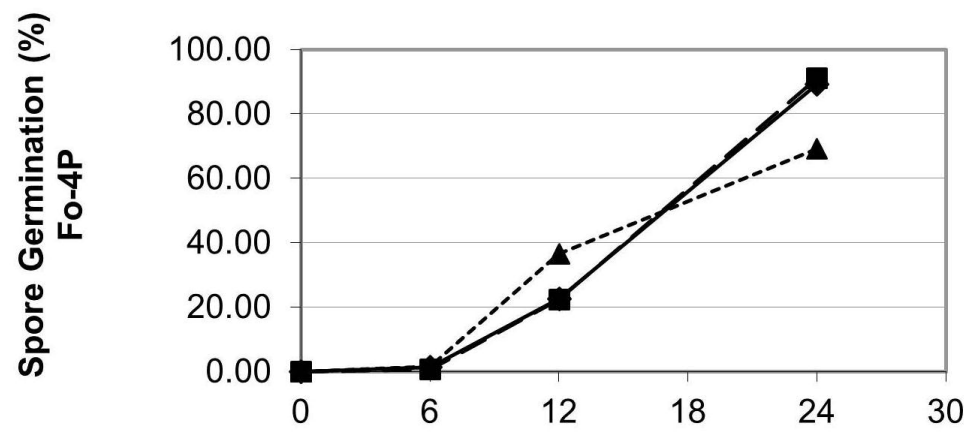

--ム-- $\mathrm{Rr}-1$

- - Ba-2

$\rightarrow$ Control

Time (hours)
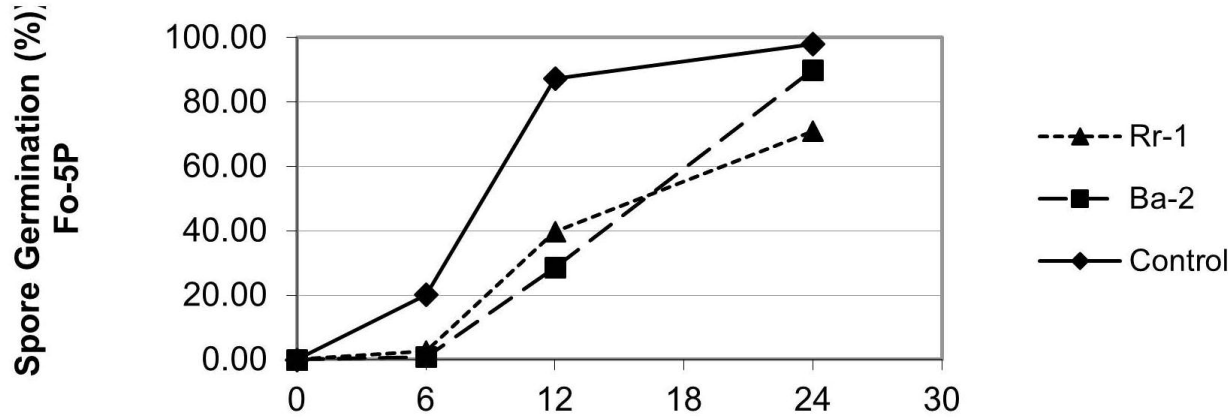

Time (hours)
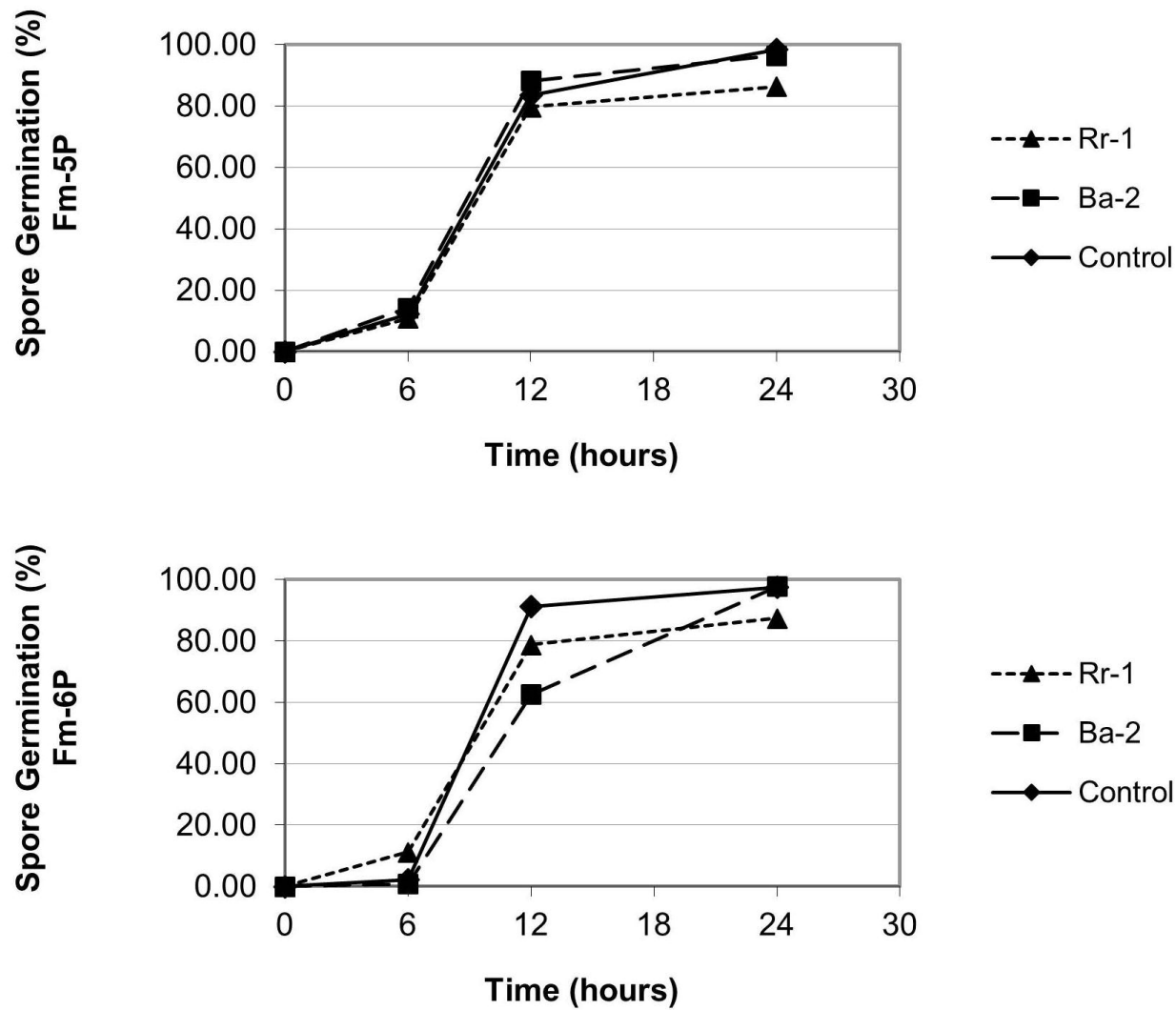

Fig. 3. Effect of culture filtrates from $R$. roseolus ( $\mathrm{Rr}-1$ ) and $B$. aereus (Ba-2) on $F$. oxysporum (Fo-4P and Fo-5P) and $F$. verticillioides (Fm-5P and Fm-6) on microconidial germination at 0, 6, 12 and 24 hours after confrontation 

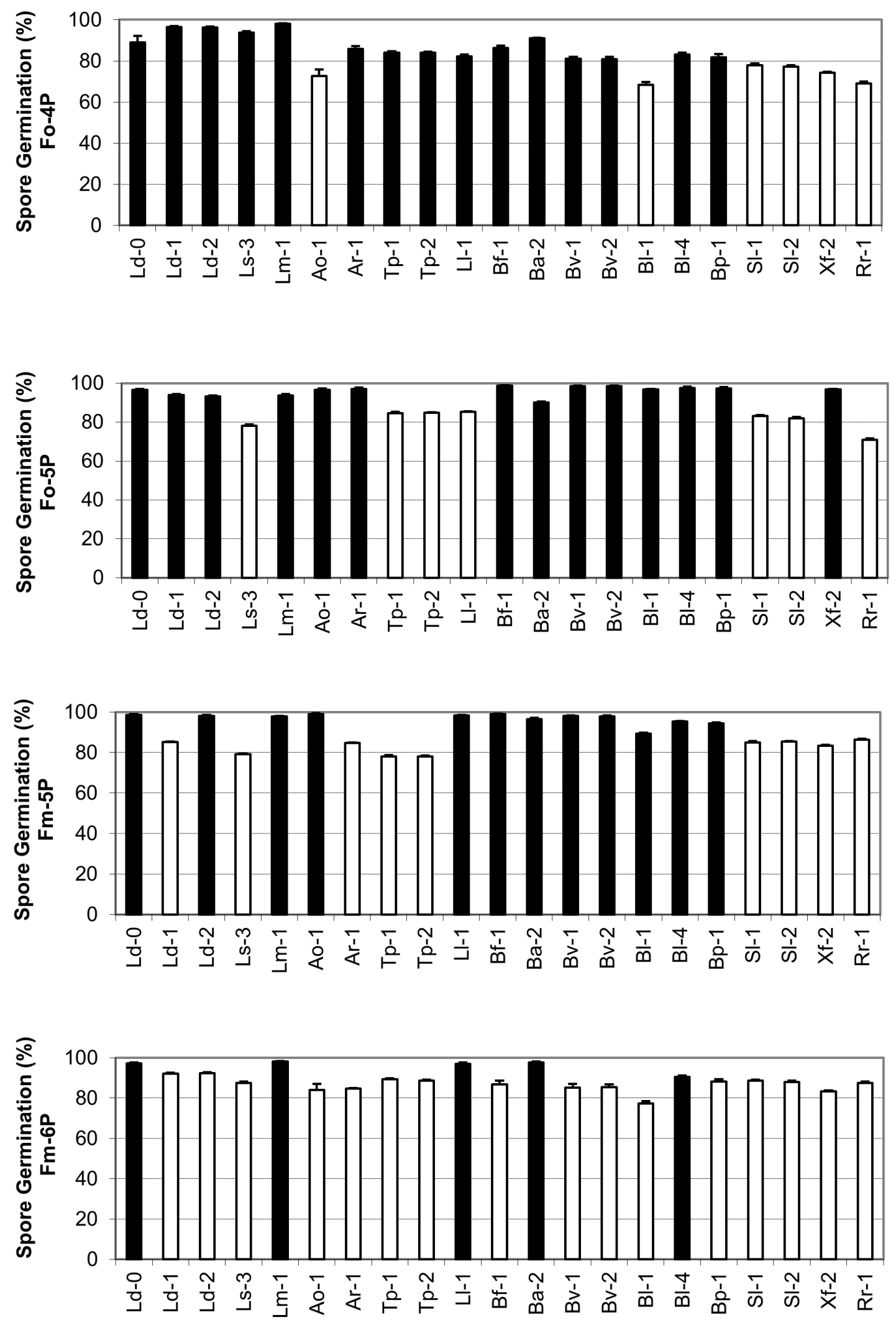

Fig. 4. Effect of culture filtrates from 21 isolates of edible ectomycorrhizal fungi on spore germination of two $F$. oxysporum isolates (Fo$4 \mathrm{P}$ and Fo-5P) and F. verticillioides isolates (Fm-5P and Fm-6P) 24 hours after addition of culture filtrate. Values are means of 1200 microconidia. Black bars represent values that are not significantly different from controls $(p<0.05$ ) 
sanguifluus (Lm-1), appeared to lack this ability, as their culture filtrates had no significant effects on Fusarium spp. spore germination.

Similar results were observed by Hwang et al. (1995) in in vitro assays, recording a reduction in F. verticillioides spore germination when treated with culture filtrates from Paxillus involutus and Bacillus subtilis (40.0\% and $55.2 \%$, respectively) and no effect on spore germination by other ECM fungi like S. tomentosus. Chakravarty and Hwang (1991) recorded that culture filtrates from Laccaria laccata reduced spore germination in F. oxysporum and postulated that this effect was probably related to the production of soluble phenols by ECM fungi. A similar in vitro mechanism of inhibition, involving the production of antimicrobial compounds, may be associated with our culture filtrates assay. Further studies should be performed to confirm the influence of the ECM phenols on the germination of Fusarium isolates. More ECM isolates showed effects against Fusarium isolates in the co-culture assay than in the conidial germination assay. It could be that the inhibitory substances produced in the agar medium, or how they are diffused, are qualitatively or quantitatively different than those produced on the culture filtrates or they affect Fusarium growth and spore germination differently. In the co-culture assay on solid media, not only antibiosis but also the effect of competition for nutrients might be involved. However, it is unlikely that the observed reduction of growth in the Fusarium isolates could be only due to a competition effect with the ECM fungi, as some isolates with vigorous growth (i.e., $\mathrm{Xf}-2$ ) failed to cause any effect on the Fusarium colonies.

Acidification of the medium as the result of the ECM in vitro growth might be another reason for the decrease in Fusarium growth, so inhibitory effects observed using unbuffered media can be misinterpreted as antibiosis (Rasanayagam and Jeffries 1992; Schelkle and Peterson 1996). Unbuffered medium was used in this study and therefore the possibility of a $\mathrm{pH}$ decrease must be considered. Olaizola (2007) analyzed the acidification of BA medium by 12 different ECM fungi and found no relationship between $\mathrm{pH}$ fluctuation by ECM and Fusarium inhibition.

ECM species such as Rhizopogon, Suillus, Laccaria or Lactarius form ectomycorrhizal roots during the first stages of seedling growth (Sanchez and García 2006) and were more effective against Fusarium than Boletus, Amanita or Xerocomus. These fungi are commonly associated with mature forests and are difficult to manage for mycorrhizal root formation in nursery seedlings. The results are confirmed in vivo, and have practical implications for the production of healthy mycorrhizal plants in nurseries, where ECM species form ectomycorrhizal roots during the first stages of seedling growth.

In vitro antagonism assays are useful for studying the production of antifungal substances by ECM fungi, as interactions with other organisms are avoided and a high number of organisms can be tested for further in vivo assays. After screening 21 ECM fungi we concluded that isolates of Suillus luteus (Sl-1), Lactarius deliciosus (Ld-1 and Ld-2), Rhizopogon roseolus $(\mathrm{Rr}-1)$ and Tricholoma portentosum (Tp-1) reduced Fusarium growth and spore germination in vitro. Therefore, these ECM fungi are considered potential candidates for in vivo biological control of $F$. oxysporum and $F$. verticillioides. Four of these fungi have already been tested in vivo (Machón et al. 2006; 2009; Olaizola 2007; Mateos et al. 20017) and we are investigating other species to determine their efficiency against Fusarium species, and their interaction with soil microorganisms, pathogens, and naturally occurring mycorrhizal fungi.

\section{Acknowledgements}

We thank Dr. Pablo Martín Pinto (University of Valladolid) for providing the Fusarium isolates, Marina Fernandez Toirán (Valonsadero Forest Research Centre, Soria, Spain) for ectomycorrhizal isolates Rr-1 and Ll-1 and Nigel Gofton, Dr. Luis Santos del Blanco and Dr. Gabriela Ritokova for reviewing this manuscript. Financial support was received from the Spanish Ministry of science and Technology, and from the European Regional Development Fund (ERDF) within the Spanish National Research Project Call (Project AGL20011771).

\section{References}

Annesi, T. and E. Motta. 1998. Hebeloma inoculation on Norway spruce seedlings in solarized and infested soil. Eur. J. Forest Pathol. 28 (3): 159-166.

Axelrood, P.E., M. Neumann, D. Trotter, R. Radley, G. Shrimpton and J. Dennis. 1995. Seedborne Fusarium on Douglas-fir: Pathogenicity and seed stratification method to decrease Fusarium contamination. New Forests 9: 35-51.

Boa, E. 2004. Wild edible fungi. A global overview of their use and importance to people. Non-Wood Forest Products 16. FAO, Rome, $160 \mathrm{p}$.

Chakravarty, P. and S.F. Hwang. 1991. Effect of an ectomycorrhizal fungus, Laccaria laccata, on Fusarium damping-off in Pinus banksiana seedlings. Eur. J. Forest Pathol. 21: 97-106.

Chakravarty, P., R.L. Peterson and B.E. Ellis. 1990. Integrated control of Fusarium damping-off in red pine seedlings. Can. J. For. Res. 20: $1283-1288$.

Chakravarty, P., R.L. Peterson and B.E. Ellis. 1991. Interaction between the ectomycorrhizal fungus Paxillus involutus, damping-off fungi and Pinus resinosa seedlings. J. Phytopathol. 132: 207-218.

Chakravarty, P., D. Khasa, B. Dancik, L. Sigler, M. Wichlacz, L.S. Trifonov and W.A. Ayer. 1999. Integrated control of Fusarium damping-off in conifer seedlings. J. Plant Dis. Protect. 106 (4): 342-352.

Diedhiou, P.M., J. Hallmann, E.C. Oerke and H.W. Dehne. 2003. Effects of arbuscular mycorrhizal fungi and a non-pathogenic Fusarium oxysporum on Meloidogyne incognita infestation of tomato. Mycorrhiza 13: 199-204.

Duchesne, L.C. 1994. Role of ectomycorrhizal fungi in biocontrol. In: Mycorrhizae and Plant Health. Pfleger FL, Linderman RG (eds). APS Press, St Paul, Minnesota, USA, pp 27-46.

Duchesne, L.C., R.L. Peterson and B.E. Ellis. 1987a. The accumulation of plant-produced antimicrobial compound in response to ectomycorrhizal fungi: a review. Phytoprotection 68:17-27.

Duchesne, L.C., R.L. Peterson and B.E. Ellis. 1987b. Pine root exudate stimulates the synthesis of antifungal compounds by the ectomycorrhizal fungus Paxillus involutus. New Phytol. 108: 470-476.

Duchesne, L.C., R.L. Peterson and B.E. Ellis. 1988. Interaction between the ectomycorrhizal fungus Paxillus involutus and Pinus resinosa induces resistance to Fusarium oxysporum. Can. J. Bot. 66: 558-562.

Duchesne, L.C., R.L. Peterson and B.E. Ellis. 1989a. The future of ectomycorrhizal fungi as biological control agents. Phytoprotection 70: 51-58.

Duchesne, L.C., R.L. Peterson and B.E. Ellis. 1989b. The time course of disease suppression and antibiosis by the ectomycorrhizal fungus Paxillus involutus. New Phytol. 111: 693-698. 
Halldórsson, G., H. Sverrisson, G. Eyjólfsdóttir and E. Oddsdóttir. 2000. Ectomycorrhizae reduce damage to Russian larch by Otiorhynchus larvae. Scand. J. For. Res. 15 (3): 354-358.

Hu, M.J., K.D. Cox and G. Schnabel. 2016. Resistance to increasing chemical classes of fungicides by virtue of "selection by association" in Botrytis cinerea. Phytopathol. 106(12): 1513-1520.

Hwang, S., P. Chakravarty and K. Chang. 1995. The effect of two ectomycorrhizal fungi, Paxillus involutus and Suillus tomentosus, and of Bacillus subtilis on Fusarium damping-off in jack pine seedlings. Phytoprotection 76: 57-66.

Kope, H.H. and J.A. Fortin. 1989. Inhibition of phytopathogenic fungi in vitro by cell free culture media of ectomycorrhizal fungi. New Phytol. 113: 57-63.

Lamichhane, J. R., C. Dürr, A.A. Schwanck, M.H. Robin, J.P. Sarthou, V. Cellier, A. Messéan and J.N. Aubertot. 2017. Integrated management of damping-off diseases: A review. Agron. Sustain. Dev. 37(2): 10.

Landeras, E. et al. 2005. Outbreak of pitch canker caused by Fusarium circinatum on Pinus spp. in northern Spain. Plant Dis. 89: 1015. Lucas, J. A., N.J. Hawkins and B.A. Fraaije. 2015. Chapter two-The evolution of fungicide resistance. Adv. Appl. Microbiol. 90: 29-92.

Machón, P., O. Santamaría, J. Pajares, F.M. Alves-Santos and J.J. Diez. 2006. Influence of the ectomycorrhizal fungus Laccaria laccata on pre-emergence, post-emergence and late damping-off by Fusarium moniliforme and F. oxysporum on Scots pine seedlings. Symbiosis 42 (3): 153-160

Machón, P., J. Pajares, J.J. Diez and F.M. Alves-Santos. 2009. Influence of the ectomycorrhizal fungus Laccaria laccata on pre-emergence, post-emergence and late damping-off by Fusarium moniliforme and F. oxysporum on stone pine seedlings. Symbiosis 49 (3): 101-109.

Martínez, R., F.M. Alves-Santos, J.A. Pajares and J.J. Diez. 2006. Effect of the ectomycorrhizal fungi Amanita rubescens on Quercus spp. seeds and seedlings inoculated with Fusarium moniliforme and F. oxysporum. In: Abstracts, $5^{\text {th }}$ International Conference on Mycorrhizae, July 23-27, 2006, Granada, Spain. No. 16.7, 231.

Martínez de Azagra, A., J.A. Oria de Rueda and P. Martínez. 1997. Estudio sobre la potencialidad de los diferentes usos del bosque para la creación de empleo en el medio rural de Castilla y León. La producción de mayor potencialidad: hongos silvestres comestibles. Iniciativa Comunitaria ADAPT. 140 p.

Martín-Pinto, P., J.A. Pajares and J.J. Diez. 2006a. In vitro effects of four ectomycorrhizal fungi, Boletus edulis, Rhizopogon roseolus, Laccaria laccata and Lactarius deliciosus on Fusarium damping off in Pinus nigra seedlings. New Forests 32(3): 323-334

Martín-Pinto, P., J.A. Pajares, V. Pando and J.J. Diez. 2006b. Fungi isolated from diseased nursery seedlings in Spain. New Forests 31: 41-56.

Martín-Pinto, P., J.A. Pajares and J.J. Diez. 2008. Pathogenicity of Fusarium verticillioides and Fusarium oxysporum on Pinus nigra seedlings in northwest Spain. Forest Pathol. 38: 78-32.

Marx, D.H. 1969. The influence of ectotrophic mycorrhizal fungi on the resistance of pathogenic infections. I Antagonism of mycorrhizal fungi to pathogenic fungi and soil bacteria. Phytopathol. 59: 153-163.

Marx, D.H. and C.B. Davey. 1969. The influence of ectotrophic fungi on the resistance to pathogenic infections. Resistance of normally occurring mycorrhizae to infections by Phytophthora cinnamomi. Phytopathol. 59: 549-558.

Mateos, E., J. Olaizola, J. Pajares, V. Pando and J. J. Diez. 2017. Influence of Suillus luteus on Fusarium damping-off in pine seedlings. Afr. J. Biotech. 16: 268-273

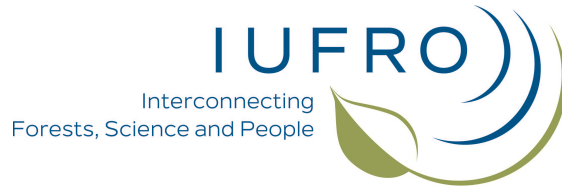

This paper is based on material that was presented at the meeting of IUFRO Working Party 7.02.02 - Foliage, Shoot and Stem Diseases, May 7-11, 2017, Niagara Falls, Ontario, Canada
Molina, R. and J.G. Palmer. 1982. Isolation, maintenance and pure culture manipulation of ectomycorrhizal fungi. In: Methods and Principles of Mycorrhizal Research (N.C. Schenck, ed.). American Phytopathological Society, St Paul. USA, pp. 115-129.

Morin, C.H., J. Samson and M. Dessureault. 1999. Protection of black spruce seedlings against Cylindrocladium root rot with ectomycorrhizal fungi. Can. J. Bot. 77: 169-174.

Neff, L. and R. Perrin. 1999. Practical Handbook of Damaging Agents in European Forest Nurseries. European commission. Luxembourg, $352 \mathrm{p}$.

Olaizola, J. 2007. Selección de hongos ectomicorrícicos comestibles para su utilización en el control biológico del damping-off causado por Fusarium oxysporum Schlecht y F. verticillioides (Sacc.) Nirenberg. PhD Thesis. University of Valladolid, Palencia, Spain.

Pedersen, E.A., M.S. Reddy and P. Chakravarty. 1999. Effect of three species of bacteria on damping-off, root rot development, and ectomycorrhizal colonization of lodgepole pine and white spruce seedlings. Eur. J. Forest Pathol. 29: 123-134.

Perrin, R. and M. Soulas. 1996. Variability in the protective effect of Laccaria mycorrhizae against Fusarium root rot of conifers. INRA, Cedex, France.

Rasanayagam, S. and P. Jeffries. 1992. Production of acid is responsible for antibiosis by some ectomycorrhizal fungi. Mycol. Res. 96: 971-976.

Rudawska, M. 2000. The role of mycorrhizas in the protecting forest trees from soil pathogens. Sylwan 144(4): 27-39.

Sampagni, R. and R. Perrin. 1985. Attempts to elucidate the mechanisms involved in the protective effect of Laccaria laccata against Fusarium oxysporum. In: Proceedings $1^{\text {st }}$ European Symposium on Mycorrhizae (V. Gianinazzi-Pearson and S. Gianinazzi, ed.). Dijon, France, pp. 799-806.

Sánchez, J.A. and A. García. 2006. Atlas de los Hongos de Castilla y León. Instituto de Restauración y Medioambiente, León, Spain, 479 p. Schelkle, M. and R.L. Peterson. 1996. Suppression of common root pathogens by helper bacteria and ectomycorrhizal fungi in vitro. Mycorrhiza 6: 481-485.

Sinclair, W.A., D.P. Cowle and S.M. Hee. 1975. Fusarium root rot of Douglas-fir seedlings: Suppression by soil fumigation, fertility management and inoculation with spores of the fungal symbiont Laccaria laccata. Forest Sci. 21: 390-399.

Trappe, J.M. 1962. Fungus associates of ectotrophic mycorrhizae. Botanical Review 28: 538-606.

Trappe, J.M. 1977. Selection on fungi for ectomycorrhizal inoculation in nurseries. Ann. Rev. Phytopathol. 15: 203-222.

Wikler, K., A.J. Storer, W. Newman, T.R. Gordon and D.L. Wood. 2003. The dynamics of an introduced pathogen in a native Monterrey pine (Pinus radiata) forest. Forest Ecol. Manag. 179: 209-221.

Zhang, R.Q., M. Tang, H. Chen, Z.Q. Tian. 2011. Effects of ectomycorrhizal fungi on damping-off and induction of pathogenesisrelated proteins in Pinus tabulaeformis seedlings inoculated with Amanita vaginata. Forest Pathol. 41: 262-269. doi: 10.1111/j.14390329.2010.00669.x

Zhang H., H. Yu and M. Tang. 2017. Prior contact of Pinus tabulaeformis with ectomycorrhizal fungi increases plant growth and survival from damping-off. New Forests 48: 855-866. doi: 10.1007/s11056-017-9601-9

Zhao, Z.P., S.C. Kuo and K.C. Bi. 1988. Selection of ectomycorrizhal fungi with resistance to Rhyzoctonia. In: Second European Symposium on Mycorrhizae. Ecological and Applied Aspects of Ecto- and Endomycorrhizal Associations, August 14-20, 1988, Praga, Poland. 28, 1-4. 